\title{
Resource mapping and emergency preparedness to infectious diseases in human and animal populations in Kibaha and Ngorongoro districts, Tanzania
}

\author{
Authors: \\ E.D. Karimuribo ${ }^{1}$ \\ B. Jones ${ }^{2}$ \\ M.I. Matee \\ D.M. Kambarage ${ }^{1}$ \\ S. Mounier-Jack ${ }^{4}$ \\ M.M. Rweyemamu ${ }^{1}$
}

\section{Affiliations:}

${ }^{1}$ Southern African Centre for Infectious Disease Surveillance (SACIDS), Sokoine University of Agriculture, Tanzania

${ }^{2}$ Royal Veterinary College, London, United Kingdom

${ }^{3}$ Department of Microbiology and Immunology, Muhimbili University of Health and Allied Sciences, Tanzania

${ }^{4}$ Communicable Disease Policy Research Group, London School of Hygiene and Tropical Medicine, United Kingdom

\section{Correspondence to:}

E.D. Karimuribo

Email:

ekarimu@yahoo.co.uk

\section{Postal address:}

Southern African Centre for Infectious Disease Surveillance (SACIDS), Sokoine University of Agriculture, Morogoro, Tanzania

How to cite this abstract: Karimuribo, E.D., Jones, B., Matee, M.I., Kambarage, D.M., Mounier-Jack, S. \& Rweyemamu, M.M., 2012, 'Resource mapping and emergency preparedness to infectious diseases in human and animal populations in Kibaha and Ngorongoro districts, Tanzania', Onderstepoort Journal of Veterinary Research 79(2), Art. \#470, 1 page. http://dx.doi. org/10.4102/ojvr.v79i2.470
A rapid situation analysis was conducted in Kibaha and Ngorongoro districts in Tanzania to map resources as well as analysing emergency preparedness to infectious diseases in animal (domestic and wild) and human populations. Kibaha was chosen as a district close to a commercial city (Dar es Salaam) while Ngorongoro represented a remote, border district with high interactions between humans, domestic and wild animals. In this study, data on resources and personnel as well as emergency preparedness were collected from all wards $(n=22)$, human health facilities $(n=40)$ and livestock facilities in the two districts using interview checklists and questionnaires. Descriptive statistics for resources were calculated and mapped by district. Kibaha district had a higher human population density, more health workers, better equipped health facilities and better communication and transport systems. On the other hand, Ngorongoro had a higher population of livestock and more animal health facilities but a poorer ratio of animal health workers to livestock. The average ratio of health personnel to population in catchment areas of the health facilities was 1:147 (range of 1:17-1:1200). The ratio of personnel to human population was significantly higher in Kibaha (1:95) than in Ngorongoro (1:203) district $(p=0<0.001)$. Considering the limited resources available to both human and animal health sectors and their different strengths and weaknesses there are opportunities for greater collaboration and resource-sharing between human and animal health for improved surveillance and emergency-preparedness.

Note: Proceedings of the Conference of the Southern African Centre for Infectious Disease Surveillance 'One Health' held at the National Institute for Communicable Diseases, Johannesburg, July 2011.

Copyright: @ 2012. The Authors. Licensee: AOSIS OpenJournals. This work is licensed under the Creative Commons Attribution License. 